\title{
Tuzak nöropatilerde ultrasonografik görüntüleme
}

\author{
Ultrasonography in nerve entrapment syndromes
}

\author{
Nuri Karabay ${ }^{1}$, Erkin Çetinkol ${ }^{2}$ \\ ${ }^{1}$ Dokuz Üylül Üniversitesi Tıp Fakültesi Hastanesi, Radyoloji Anabilim Dalı, İzmir \\ ${ }^{2}$ EMOT Hastanesi, Radyoloji Kliniği, İzmir
}

\begin{abstract}
Tuzak nöropatinin erken dönemde tanınması, sinir fonksiyonlarının geri dönebilmesi açısından önemlidir. Görüntüleme yöntemleri, tuzak nöropatinin yerini ve etiyolojisini kesin bir şekilde ortaya koymada önemli bilgiler sağlamaktadır. Ultrasonografi, sinirin kendisini gösterebiliyor olması, yüksek çözünürlüklü görüntüler sağlayabilmesi, esnek bir görüntüleme alanına ve düzlemine sahip olması, hızlı, ucuz, ağrısız olması ve invaziv olmaması nedeni ile, ilk sırada tercih edilen görüntüleme yöntemidir. Ultrasonografi, tanı aşamasında olduğu kadar tedavi amaçlı uygulamalara kılavuzluk edebilmektedir. Bu makalenin amacı, periferik sinirlerin ultrasonografik değerlendirmesi konusunda temel bilgileri vermek, üst ve alt ekstremitede sık görülen tuzak nöropatilerde görülen ultrasonografik bulguları ortaya koymaktır.
\end{abstract}

Anahtar sözcükler: tuzak nöropati; ultrasonografi; periferik sinir
Early diagnosis of entrapment neuropathies is important for the recovery of nerve functions. Imaging methods provide a useful diagnostic aid to clinicians about nerve and cause of entrapment. Ultrasonography should be the first preferred imaging method which is an easily accessible, cheap, rapid, and noninvasive imaging technique; it also demonstrates nerve itself. Ultrasonography can be used not only in diagnosis of entrapment neuropathies, but also as a guide during treatment. The purpose of this article is to demonstrate the ultrasonographic findings in the most common nerve entrapment syndromes, and to give basic information about the peripheral nerve ultrasonography.

Key words: nerve entrapment syndrome; ultrasonography; peripheral nerve

\section{ÖĞRENME NOKTALARI}

- Ultrasonografi (US), tuzak nöropatilerin tanı ve tedavisinde kullanılabilecek yardıma bir görüntüleme yöntemidir.

- US, periferik sinirin kendisini gösterilebilir ve komşu dokular hakkında bilgi verebilir.

- US, diğer tanısal yöntemlere göre ağrısız, kolay ulaşılabilir ve ucuz bir yöntemdir.

Üst ve alt ekstremitede yer alan sinirler, seyirleri boyunca geçtikleri fibröz veya fibro-osseöz tüneller içerisinde sıkışmaya maruz kalabilmekte ve etkilenen sinirin yapısına göre, motor veya duysal bulgular ortaya çıkmaktadır. Ayrıca, sinirin kompresyonuna, yer değiştirmesine, gerilmesine veya sinirin kendi patolojisine bağı tuzak nöropatiler de gelişebilmektedir. Tedavi, sinirin sıkışmasının yeri, etiyolojisi, kronisitesi ve mevcut sinir hasarının yaygınlığı ile ilişkilidir; bu nedenle, tuzak nöropatinin erken dönemde tanınması, sinir fonksiyonlarının geri dönebilmesi açısından önemlidir. Tuzak nöropati tanısı, fizik muayene ve elektrodiagnostik testler ile, genellikle başarılı bir şekilde konulur. Ancak, i) elektrofizyolojik bulguların klinik ile uyuşmadığı veya non-spesifik olduğu durumlarda tanının desteklenmesi amacıyla, ii) bir sinirde birden fazla noktada tutulum düşünülüyor ise, iii) sinir kompresyonunu taklit edebilen patolojilerin varlığı düşünülüyor ise, görüntüleme yöntemlerine başvurulur. Görüntüleme, tuzak nöropatinin yerini ve etiyolojisini (kitle, anormal kas, osseöz deformite vb.) belirlemede veya nöropati ile karışabilecek diğer nedenleri ortaya koymada önemli bilgiler sağlar.

Direkt radyografi, osseöz yapıları (örneğin; kırı, dislokasyon, kallus, osteofit, ekzositoz vb.) değerlendirmede ilk basamak görüntüleme yöntemidir. Tuzak

- İletişim adresi: Yrd. Doç. Dr. Nuri Karabay, Dokuz Eylül Üniversitesi Tıp Fakültesi Hastanesi, Radyoloji Anabilim Dalı, İnciraltı Yerleşkesi, 35340 Balçova, İzmir Tel: 0532 - 7710554 e-posta: nurikarabay@gmail.com

- Geliș tarihi: 13 Ekim $2015 \quad$ Kabul tarihi: 13 Ekim 2015 
nöropatilerin sık görüldüğü fibro-osseöz tünellerin direkt grafi ile değerlendirilebilmesi için, genellikle özel pozisyonlara ihtiyaç duyulur. Direkt grafinin yetersiz kalması veya kemik yapılar hakkında daha fazla bilgi edinilmek istenmesi halinde, bilgisayarlı tomografi (BT)'ye başvurulmalıdır. Sinirin kendisinin gösterilmesinde manyetik rezonans (MR) görüntüleme ve US, tercih edilmesi gereken görüntüleme yöntemleridir. $M R$, üstün yumuşak doku kontrastı sağlaması nedeni ile tercih edilen yöntem içerisinde yer almasına rağmen, US'nin en önemli yönlerinden biri, kullanım avantajlarıdır. US, tuzak nöropatilerde, tanı aşamasında olduğu kadar tedavi aşamasında da kullanılabilmektedir.

Bu makalenin amacı, periferik sinirlerin ultrasonografik değerlendirmesi konusunda temel bilgileri vermek, üst ve alt ekstremitede sık görülen tuzak nöropatilerde görülen ultrasonografik bulguları ortaya koymaktır.

\section{PERIFERIK SINIR ULTRASONOGRAFISININ STANDARTLARI VE NORMAL SINIRIN ULTRASONOGRAFIK GÖRÜNÜMÜ}

Yeterli bir ultrasonografik değerlendirme için, periferik sinir anatomisinin ve ultrasonografik görünüm özelliklerinin bilinmesi, US tekniğinin doğru bir şekilde uygulanması ve optimize edilmesi gereklidir. Genel olarak, US sistemlerinde yüksek frekanslar ve yüksek görüntü çözünürlüğü sağlanırken, küçük yapıların görüntülenmesine ve ince ayrıntıların ortaya konmasına olanak tanınır. Bu nedenle, periferik sinir sisteminin ultrasonografik değerlendirmesinin yüksek çözünürlüklü (en az 12-18 MHz), lineer dizilimli transduserler ile yapılması gerekmektedir. Yüksek frekanslı transduserler, yakın plan odaklama özellikleri nedeni ile, yüzeyel seyreden sinirlerin görüntülenmesinde oldukça etkindir. Ancak, yüksek frekanslı ses dalgalarının doku penetrasyonu düşüktür, yani, derin dokuların görüntülenmesinde başarı azalmaktadır; bu nedenle, siyatik sinir gibi derin yerleşim gösteren yapıların görüntülenmesinde, daha düşük frekanslı (5-7,5 MHz), kurvilineer transduserler tercih edilmelidir. Ultrasonografik değerlendirme sırasında, incelenen tüm yapılar, hem transvers (kısa), hem de longitudinal (uzun) aks olmak üzere, en az iki planda görüntülenmelidir. Cilde yakın seyreden sinirlerin değerlendirmesi için jel yastıkçıkları kullanılabileceği gibi, ultrasonografik jelin bol miktarda kullanılması da benzer işlev görebilmektedir.

Ultrasonografik değerlendirmede en önemli teknik ayrıntı, periferik sinirlerin ultrasonografik görünüm özelliklerinin (ekopatern) bilinmesidir. Normal sinir, longitudinal düzlemde, hiperekojen bir kılıf tarafindan çevrelenmiş hiperekojenik bantlar tarafindan ayrılmış, multipl hipoekoik paralel alanlara sahip, lineer bir yapı olarak izlenir. Transvers düzlemde ise, hiper ve hipoekoik noktalardan oluşmuş oval veya yuvarlak bir yapı olarak görülür; hipoekoik alanlar, nöral fasiküllere karşılık gelmekte ve bu görünüm bal peteğine benzetilmektedir (Şekil 1). Sinirin kesit alanı, sinirden sinire ve aynı sinirin farklı düzeylerine göre değişkenlik gösterebilir.

$\mathrm{Bu}$ sistematik değerlendirme, sinirin lineer yapıdaki diğer ekojenik dokulardan (tendon, aponevroz vb.) ayrımında önemlidir. Sinir değerlendirmesi sırasında sık karşılaştırılan sorunlardan birisi, sinir ve tendon ayrımının yapılmasıdır. Tendonlar da benzer görünüme sahiptir, ancak genellikle sinirlere göre daha ekojenik olur ve fibriller bir ekopatern ortaya koyar. Gerçek-zamanlı değerlendirme sırasında, ekstremiteye aktif ve pasif olarak yapılan fleksiyon-ekstansiyon hareketi ile tendonda görülen hareket, tendon-sinir ayrımı için oldukça yararlı bir manevradır. Yine, ses demeti incelenen yapılara tam dik olarak geldiğinde, periferik sinirin ekojenitesi komşu kas dokusuna göre biraz daha yüksek ekojenitede iken, tendon ekojenitesi biraz daha düşük olarak izlenir.

İnceleme yapılırken transduserin sinire dik planda tutulması, anizotropi adı verilen ve sinir ekojenitesinde azalmaya neden olarak patolojiler ile karışabilecek artefakttan kaçınılması için önemlidir. Bir sinir ultrasonografik olarak değerlendirilirken, karşı taraf ekstremitedeki aynı sinir görüntülenerek, sinir ekojenitesi ve kalınlığı karşılaştırılabilir; böylece, sinirdeki ufak değişikliklerin saptanması mümkün hale gelir. Renkli ve Power Doppler US ile, vasküler landmark'lar tanınabilir veya sinir çevresindeki dokuların vaskülaritesi değerlendirilebilir.

\section{US'NIN AVANTAJLARI VE SINIRLILIKLARI}

Sinir ileti çalışmaları ve elektromiyografi fizyoloji konusunda ayrıntılı bilgi verirken, US anatomi konusunda bilgi verir. Sinirin kendisinin görüntülenmesinde kullanılabilen iki görüntüleme yöntemi karşılaştırıldığında, yüksek çözünürlüklü US, MR'ye göre daha fazla anatomik ayrıntı ortaya koyar. Ayrıca, US ile MR karşılaştırıldığında, birincisi çok daha esnek bir görüntüleme alanına ve düzlemine sahiptir; US ile incelenen herhangi bir sinir, tüm trasesi boyunca kesintisiz olarak görüntülenebilir (konvansiyonel MR'de, genellikle önceden belirlenmiş standart kesitler kullanıldığı için, bu mümkün olmamaktadır). US, elektrofizyolojik testler veya fizik muayene ile saptanan bulguya odaklanabilir. Karşı sağlam sinir ile karşılaştırmalı değerlendirme yapmak veya sıkışan sinirin sağlam olan daha proksimal ve distal düzeylerini aynı görüntüleme seansı sırasında değerlendirmek, hızla ve kolay bir şekilde yapılabilir. Yine USG, elektrofizyoloji çalışmaları için kullanılacak iğne için veya tedavi amacı ile yapılacak enjeksiyonlar için kılavuzluk sağlayabilmektedir. US kılavuzluğunda, 

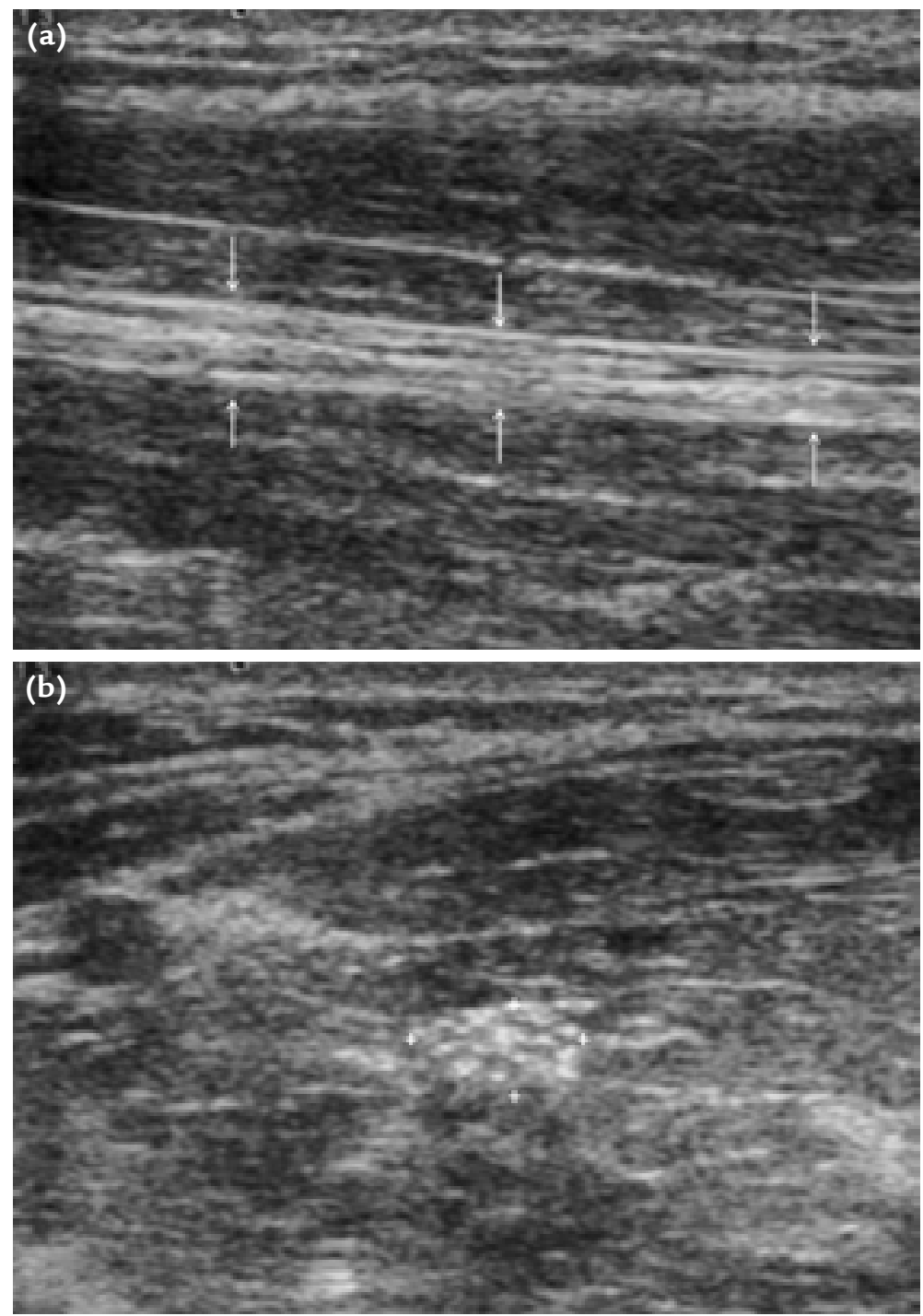

Şekil 1. a, b. Normal periferik sinirin ultrasonografik görünümü. Median sinire ait uzun aks değerlendirmede (oklar, a), sinir içerisinde hipoekoik fasiküller görülmektedir. Transvers aks görüntüde (kürsörler, b) periferik sinirin fasiküler yapısına bağlı ekojenik matriks içerisinde hipoekoik noktalar (bal peteği görünümü) izlenmektedir.

karpal tünel veya supraskapuler oluktaki gangliyon kistleri aspire edilebilir. US'nin hızlı, ucuz, ağrısız olması ve radyasyon içermemesi, klasik olarak bilinen diğer özellikleridir. Bu özellikleri, özellikle çocuk hastalarda oldukça önem kazanmaktadır.

US'nin tuzak nöropati değerlendirmesindeki en büyük kısıtlıığı, kullanıcı bağımlı olmasıdır; sinir ve çevre yapı anatomisi bilgisinin yetersiz olması halinde, yanlış yorumlamalar yapılabilmektedir. Ayrıca, ekstremitelerin proksimalinde ve derinde seyreden sinirlerin ve bu düzeyde yer alan lezyonların görüntülenmesinde, US yetersiz kalabilir.

\section{SIKIŞMA SENDROMLARINDA GÖRÜLEN EN YAYGIN US BULGULARI}

Tuzak nöropatilerin ultrasonografik değerlendirmesinde görülen en yaygın görüntüleme bulgusu, sıkışma bölgesinin proksimalinde, sinirde kalınlaşmadır (Şekil 2). Bu kalınlaşma, fokal lezyondan ziyade, genellikle fuziform bir genişleme tarzındadır. Değerlendirmede, genellikle sinirin kesit alanının ölçümü kullanılır ve ölçüm, sinirin en kalın olduğu yerden yapılmalıdır. Bazı tuzak nöropati sendromlarında izlenen kalınlık artışları için kullanılabilecek değerler, Tablo 1'de özetlenmiştir. 


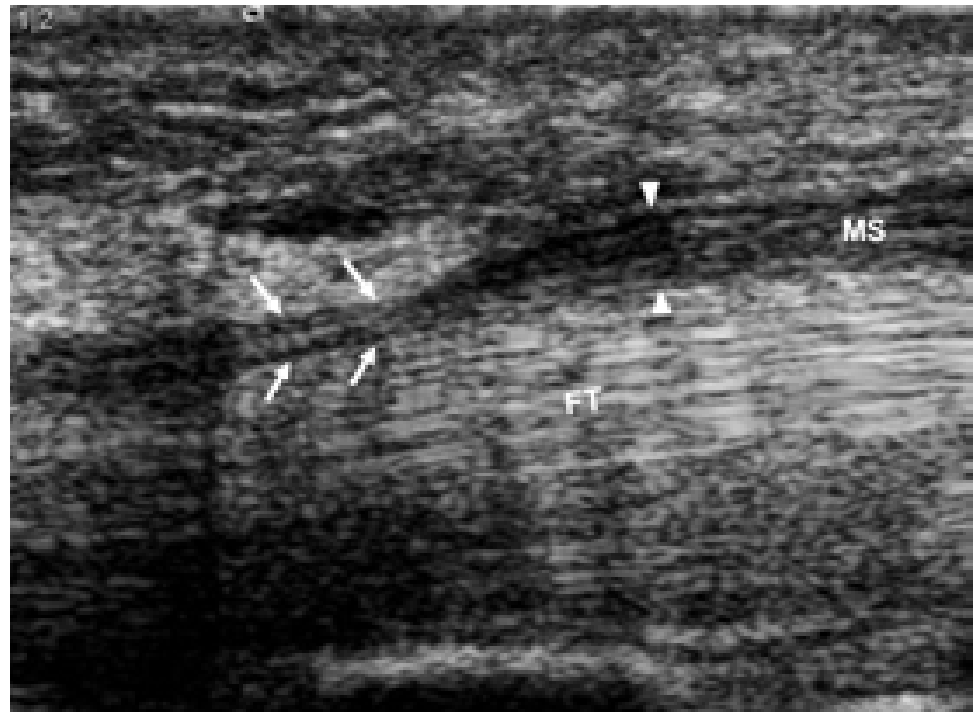

Şekil 2. Karpal tünel sendromlu bir hastada, median sinirin (MS) uzun aks görüntüsünde, transvers karpal bağ basısına bağlı, bası bölgesinde düzleşme (oklar); bası bölgesinin hemen proksimalinde kalınlık artışı (ok başları) izlenmektedir (FT, fleksör tendonlar).

Sık görülen diğer bir ultrasonografik bulgu, sıkışma bölgesinde, sinirde incelme ve düzleşmedir (Şekil 2).

US'de görülebilen diğer sıkışma bulguları ise; basıya uğramış sinirde meydana gelen intranöronal ödeme bağlı sinir içerisindeki ekojenik çizgilenmelerin kaybolması (uzun aksta fasiküler yapıda, kısa aksta ise bal peteği görünümünde kayıp) ve kalınlaşmış, tümüyle hipoekoik görünümde bir sinir segmentinin ortaya çımasıdır (Şekil 3).

Renkli ve Power Doppler US ile, sinir içerisinde vaskülarite artışı bazı olgularda gösterilebilmektedir. Normal sinirlerde vaskülarite izlenmezken, sıkışma sonucu gelişen inflamasyona bağlı sinirde intranöral kan akımı izlenebilir, ancak bu bulgunun tanısal değeri ve klinik kullanımı oldukça azdır.

Tablo 1. En sık görülen tuzak nöropati sendromlarında sinir kesit alanı değerleri

\begin{tabular}{lc}
\hline Tuzak nöropati sendromu & Sinirin kesit alanı \\
\hline Karpal tünel sendromu & $>11 \mathrm{~mm}^{2}$ \\
Kübital tünel sendromu & $>9 \mathrm{~mm}^{2}$ \\
Radyal sinir sıkışması & $>6 \mathrm{~mm}^{2}$ \\
Fibular sinir sıkışması & $>12 \mathrm{~mm}^{2}$
\end{tabular}

Yaygın ve sık kullanılan bir bulgu olmamakla birlikte, tuzak nöropatilerde, özellikle üst ekstremitede, sinir mobilitesinde değişiklik de bildirilmiştir. Karpal tünel sendromunda mobilite azalırken, kübital tünel sendromunda arttığı, sinirde subluksasyonların geliştiği gösterilmiştir.

Görüntüleme sırasında, sıkışan sinir kadar komşuluğunda yer alan dokular da, olası etiyolojik neden açısından değerlendirilmelidir. Anatomik varyasyonlar, heterotopik kemik oluşumları, kist, tümör veya aberran kas dokuları, en sık görülen nedenlerdendir ve US ile tanınmaları mümkündür. Sık görülebilen bir etiyolojik neden olan gangliyon kistleri, yuvarlak veya oval yapıda, genellikle düzgün sınırlı ve lobüle konturlu, ince duvarlı anekoik yapılar olarak görülür (Şekil 4). Gangliyon kistinde inflamasyon gelişmesi halinde, duvar kalınlığı artar, sınırlarında silinme ile birlikte iç yapısında ekojenik odaklar ortaya çıkar.

Aksesuvar kaslar, sık görülen diğer bir etiyolojik neden olup, karakteristik olarak vücudun diğer bölgelerinde yer alan kas dokularına benzemeleri nedeni ile kolaylıkla tanınır (Şekil 5).

Sinir kılıfı tümörleri, sinir ile devamlılık gösteren, genellikle hipoekoik yapıda fuziform kitleler şeklindedir ve renkli Doppler incelemede içyapısında artmış vaskülarite izlenebilir. Schwannoma'lar, yuvarlak veya oval yapıda, iyi sınırlı, sinirin aksına göre ekzantrik yerleşimli, içerisinde kistik alanlar içeren ve bu nedenle posterior güçlenme artefaktı oluşturan kitleler olma eğilimindedir. Nörofibromlar, daha lobüle görünümde ve sinir 


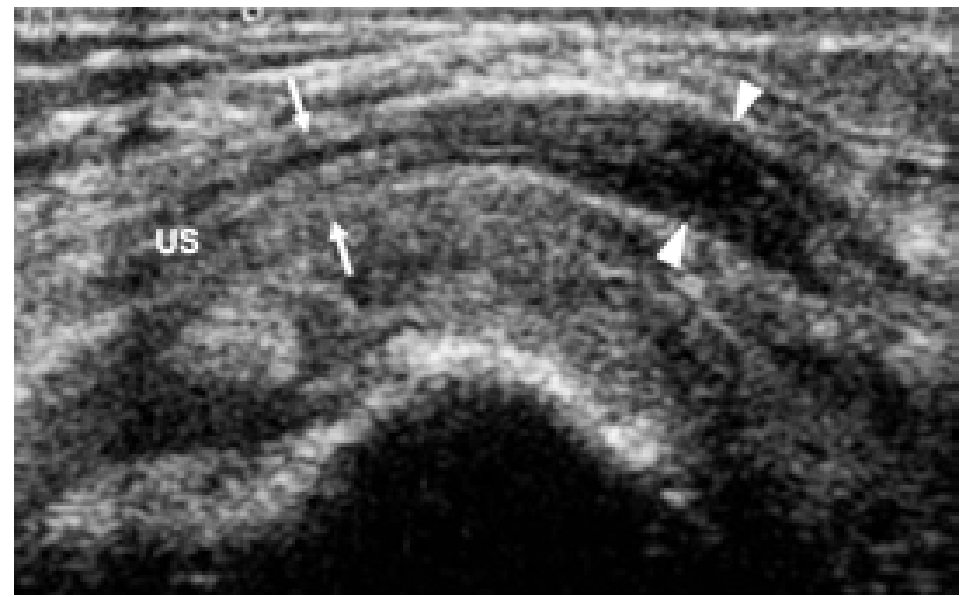

Şekil 3. Kübital tünel sendromunda, ulnar sinirde (US) sıkışma bölgesinde kalınlık artışı ve eko-yapısında bozulma (ok başları) gözlenmektedir. Sıkışma bölgesinin proksimalinde (oklar) izlenen normal ekojenik çizgilenmeler, sıkışma bölgesinde ortadan kalkmış, sinir hipoekoik hale gelmiştir.

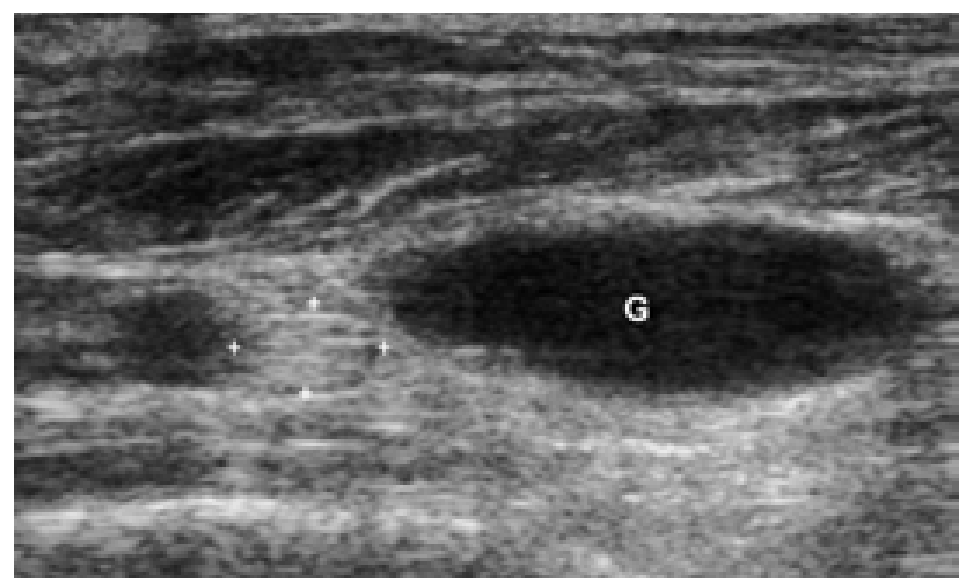

Şekil 4. Ayak bileği düzeyinde, FHL tendon kılıfı kökenli ovoid yapıda ve anekoik görünümdeki gangliyon kistinin (G) plantar sinire (kürsörler) basısı izlenmektedir.

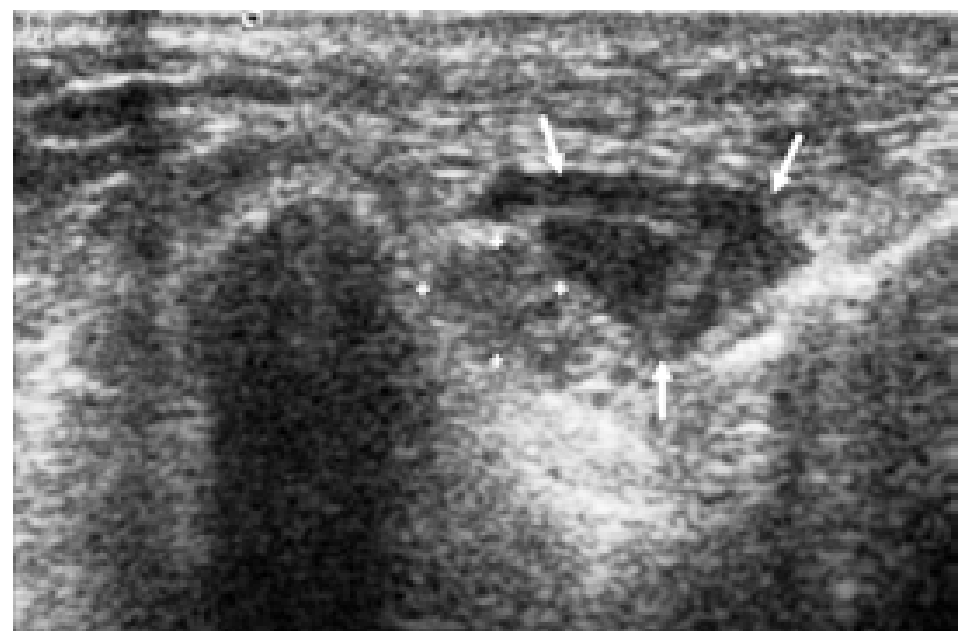

Şekil 5. Kübital tünel sendromlu hastanın kısa aks US görüntüsü, tünel içerisinde yer alan ve tünelde daralmaya neden olan ankoneus epitroklearis kasının (oklar) ulnar sinire (kürsörler) basısını göstermektedir. Kas, üçgen şeklinde, hipoekoik bir yapı olarak izlenmektedir. 


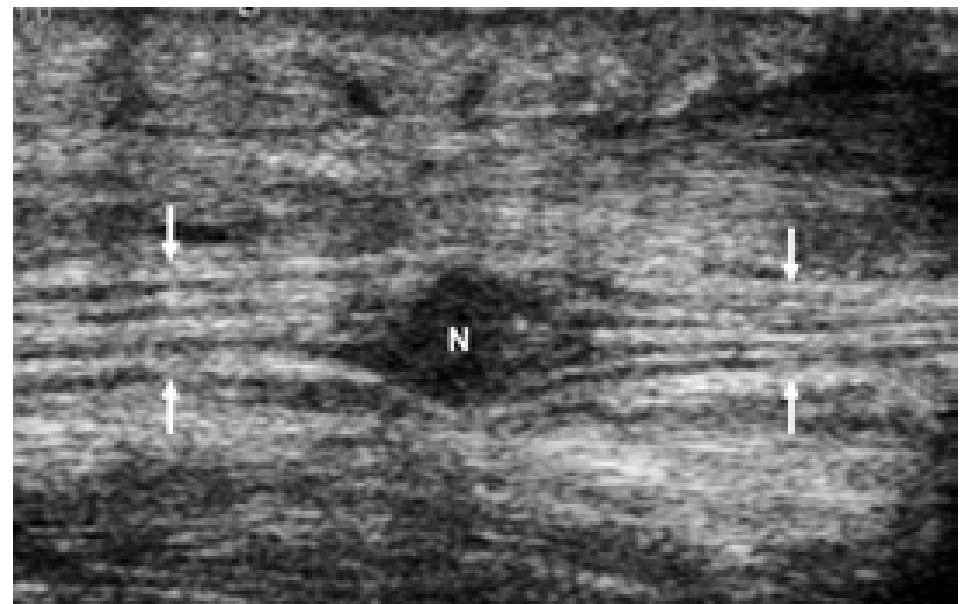

Şekil 6. Travmatik nöroma. Uzun aks US görüntüsünde, yaralanma bölgesinde, sinirin fasiküler yapısında bozulma ve nöromaya (N) ait hipokoik görünümde fuziform kalınlık artışı izlenmektedir. Oklar, sinirin normal olduğu proksimal ve distal kesimlerini göstermektedir.

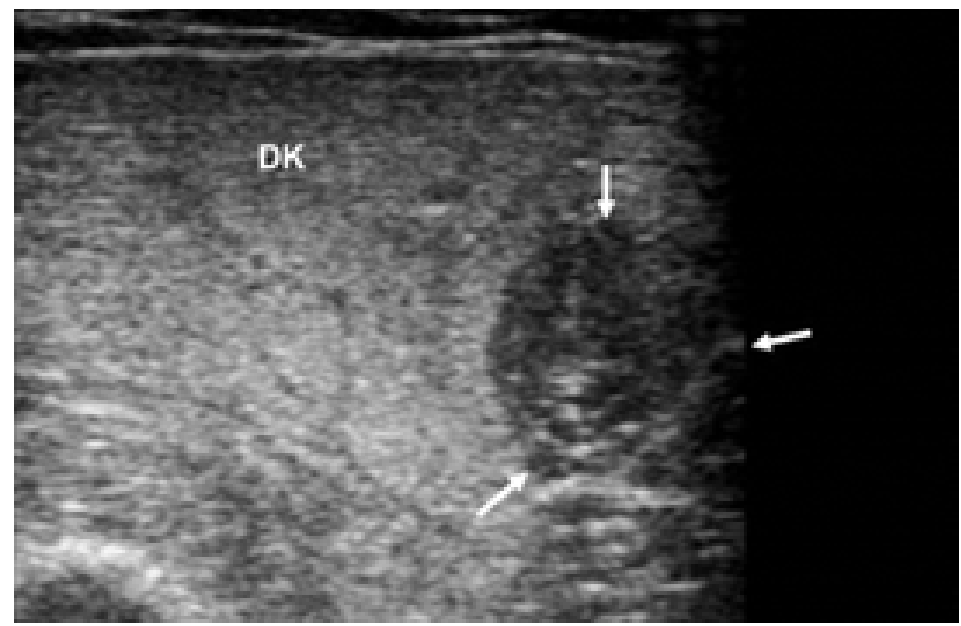

Şekil 7. Kronik denerve kasta (DK) yağ replasmanına bağlı hiperekojen görünüm mevcuttur. Oklar ile gösterilen alanda, normal kas dokusu hipoekoik olarak izlenmektedir.

boyunca uzanım gösteren kitle lezyonu olarak izlenir. Travmatik nöromalar, sinir trasesinde hipo veya hiperekoik görünümde, yuvarlak veya ovoid yapıda kitle lezyonları olarak izlenir (Şekil 6).

Sinir bulgularına ek olarak, kasta akut ve kronik dönemde değişiklikler olabilmektedir. Akut dönemde kasta ödem izlenmekte olup, genellikle kasın iç yapısında bozulma olmaksızın, kalınlık artışı şeklinde görülür; bazen kas daha hipoekoik hale gelebilir. Kas değişiklikleri, karşı ekstremite ile karşılaştırmalı değerlendirme yapılarak, kolaylıkla saptanabilmektedir. Kronik denerve kas, atrofiye gider ve yağ replasmanına bağlı olarak, hiperekojen hale gelir (Şekil 7). Bu nedenle, sinir incelemesinin sonunda, sinirin innerve ettiği kas grubu da değerlendirilmelidir. Kas atrofisine neden olabilecek bir diğer neden olan tendon rüptürlerini de aynı seans içerisinde değerlendirmek mümkündür.

\section{ÜST EKSTREMITE}

US, üst ekstremite tuzak nöropatilerinde sıklıkla kullanılan bir tanısal araçtır. ${ }^{[1-7]}$

\section{Radyal Sinir Tuzak Nöropatileri}

\section{Spiral Oluk Sendromu}

Radyal sinir, aksillayı terk ettikten sonra, humerus şaftının posterolaterali boyunca spiral oluk içerisinde 

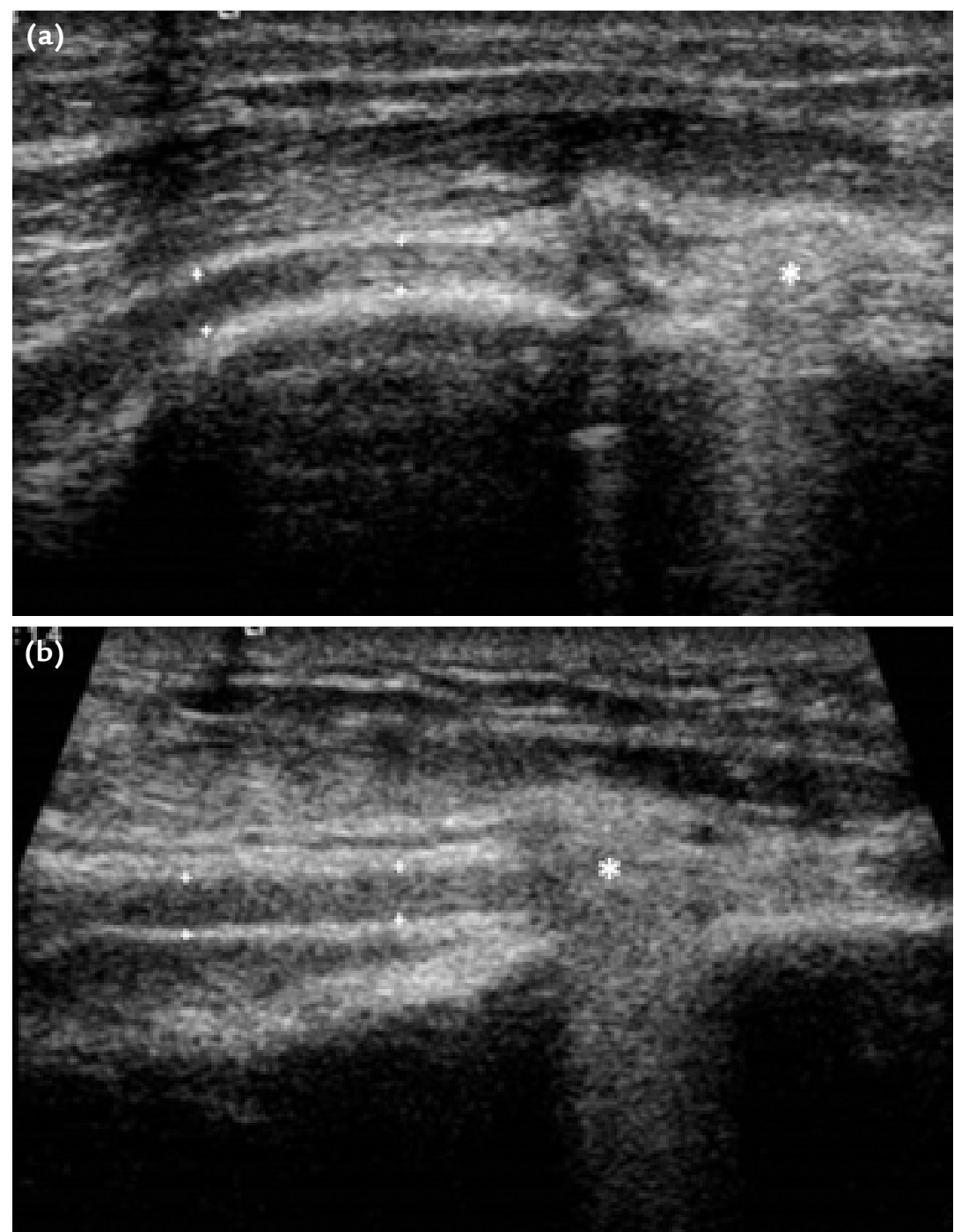

Şekil 8. a, b. Humerus kırığı sonrası radyal sinir felci gelişen hastada, uzun aks ultrasonografik görüntülerde (a, b), radyal sinirde (kürsörler) kırık hattı düzeyindeki kallus dokusuna (yıldız) bağlı devamsızlık izlenmektedir.

seyir gösterir. Kemik ile olan bu yakın seyir nedeni ile, US'de, özellikle transvers görüntülerde oldukça kolay görüntülenebilir. Bu düzeyde sinir kalınlığının, normal bireylerde, laterolateral çapı 4,0-4,2 mm, AP çapı 2,3-3,5 mm olarak bildirilmiştir. Sinir, humerus korteksinin yakın komşuluğu bulunması nedeni ile, dıştan basılara karşı oldukça açıktır; en sık olarak, uyku sırasında kolun uygun olmayan pozisyonlarda bulunması ile basıya bağlı veya humerus şaft kırıklarında kırık parçalar tarafından direkt kontüzyon veya laserasyon ile yaralanabilir. Bası veya sıkışma sonucu gelişen radyal sinir lezyonlarında, US'de sinirde kalınlık artışı, hipoekoik görünüm ve fasiküler paternde kayıp gözlenir. Kırık olgularında ise malalignment veya parçalı kırığa bağlı sinir bütünlüğünde bozulma (kesi), sinirde yer değiştirme veya interpozisyon görülebilir. Cerrahi sonrası veya kırık iyileşmesi döneminde, sinir kallus dokusu tarafından çevrelenebilir veya cerrahi donanım tarafından yaralanabilir veya itilebilir (Şekil 8). Bu gibi durumlarda, sinirin kendisinin direkt görüntülenmesi, nöropatinin etiyolojisinin ortaya konmasında ve erken dönemde cerrahi tedaviye karar verilmesinde büyük önem taşımaktadır.

\section{Posterior Interosseöz Nöropatisi (Supinator Sendrom)}

US'de, posterior interosseöz sinir (PIOS), derin ve yüzeyel supinatör kas arasında bulunan, hiperekojen görünüme sahip konnektif doku içerisinde hipoekoik 

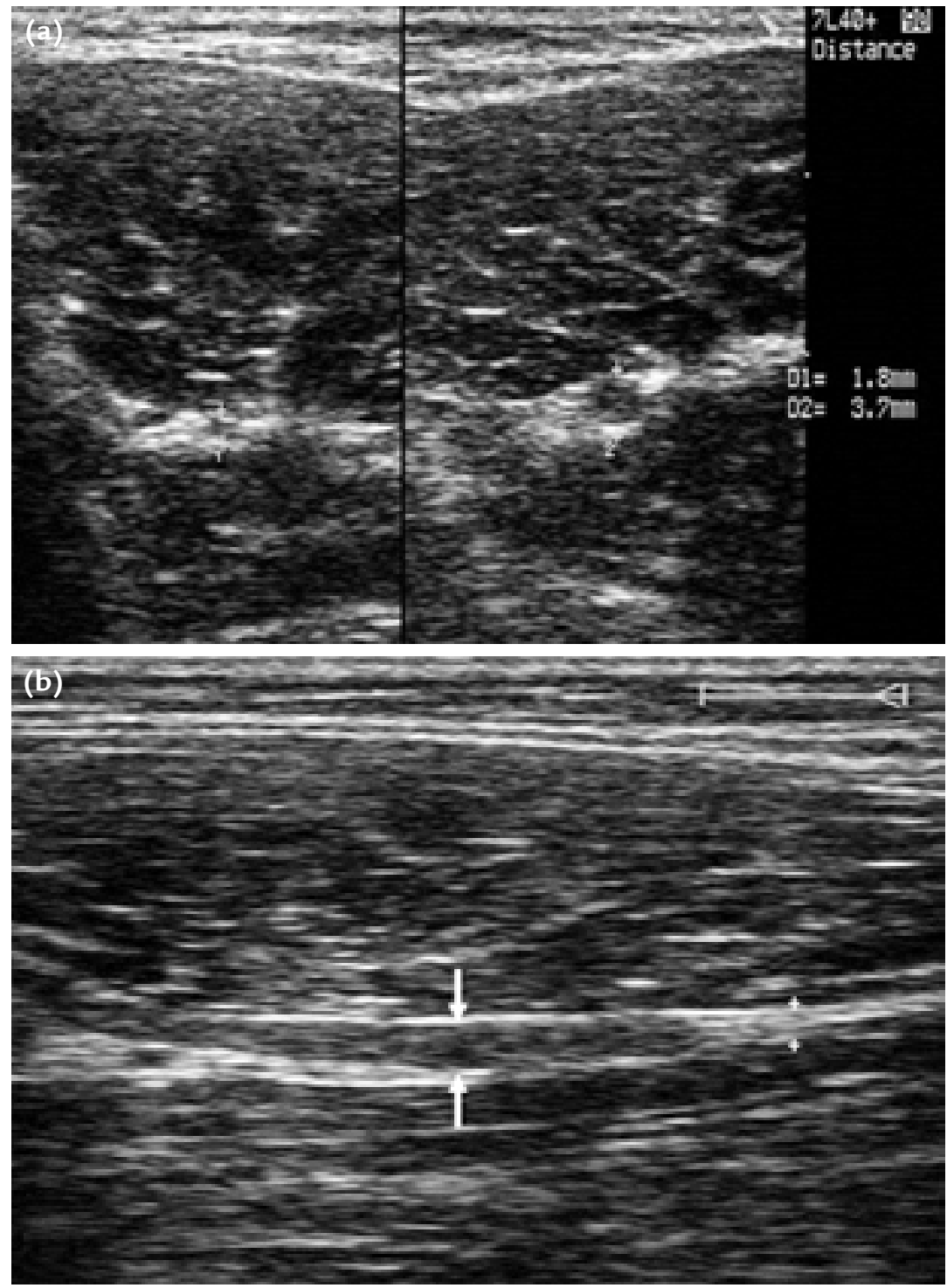

Şekil 9. a, b. Kısa (a) ve uzun (b) aks görüntülerde PiOS'ta (kürsörler) kalınlık artışı ve hipoekok görünüm. Kısa aks (a) görüntüde, karşı PiOS ile karşılaştırmalı değerlendirmede, sinirdeki kalınlık artışı; uzun aks görüntüde (b) aynı sinirin proksimal segmenti ile karşılaştırıldığında, sinirdeki kalınlık artışı ve fasiküler yapıdaki bozulma (oklar) daha net olarak izlenmektedir.

görünümdeki fasikülleri nedeniyle, kolaylıkla görüntülenebilen ovoid bir yapı olarak izlenir. Sinirin görüntülenmesi, en iyi, dirsek hafif fleksiyonda inceleme masasına konmuş şekilde iken, önkolun transvers düzlenme taranması ile gerçekleştirilebilir. Elin ekstansiyonu ve pronasyonu sırasında, sinirde Fröhse arkı düzeyinde akut bir açılanma gelişebilir ve bu durum, patolojik olarak değerlendirilmemelidir. PiOS, ark düzeyinde fibröz bantlar, rekürrent radyal damarlar veya supinator kasın kendisi tarafından sıkıştırılabileceği gibi, bu lokalizasyonda yer alan lipom veya gangliyon benzeri kitlesel lezyonlar tarafından da basıya uğratılabilir. Radius başı veya boyun kırıkları, Monteggia kırıklı-çıkığı, radyal tünel boyunca herhangi bir düzeyde sinirde gerilmeye veya yaralanmaya neden olabilir. US'de, komprese sinir, ödeme bağlı kalınlaşmış ve hipoekoik olarak izlenir (Şekil 9). Kırık ve çıkık durumlarında, sinir bütünlüğündeki bozulma yanı sıra, sinirde çap artışı veya yer değişikliği de izlenebilir. Travma olgularında, sinir komşuluğunda kemik parça, geç dönemde ise skar dokusu tarafından çevrelenmiş sinir görüntülenebilir. 


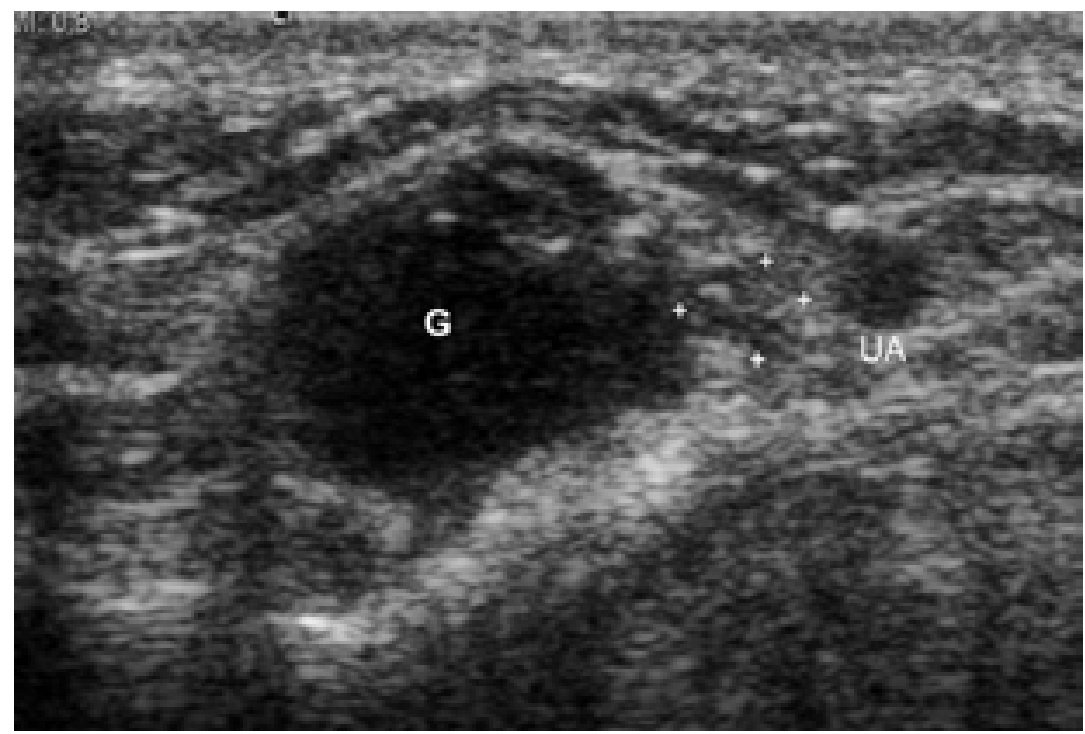

Şekil 10. Guyon kanalında ulnar sinire (kürsörler) bası oluşturan gangliyon kisti (G). Gangliyon kist, ovoid yapıda hipoekoik kitlesel lezyon olarak izlenmektedir, (UA, ulnar arter).

\section{Ulnar Sinir Tuzak Nöropatileri}

\section{Kübital Tünel Sendromu}

Ulnar nöropati, üst ekstremitede karpal tünel sendromundan sonra görülen en sık tuzak nöropatidir ve hem kondiller oluk hem de arkuat bağ düzeyinde görülebilmektedir. Kübital tünelin ultrasonografik değerlendirmesi, hastanın dirseği tam ekstansiyonda iken, mediyal epikondil ve olekranon düzeyinden yapılan transvers asktaki düzlemde gerçekleştirilir. Bu pozisyonda, sinirin yakın yerleşimli iki kemik çıkıntı arasında yer alması nedeniyle, görüntülemede küçük boyutlu transduserlerin kullanımı kolaylık sağlar. Kübital tünelin şekli, dirsek fleksiyonu ile değişebilmektedir ve buna bağlı olarak, sinirde düzleşme veya uzama görülebilir; bu nedenle, değerlendirme hem fleksiyon hem de ekstansiyonda gerçekleştirilmeli ve dinamik impingement açısından dikkatli olunmalıdır. Humeral oluk içerisinde, ulnar sinir, epikondil yakınında ovoid bir yapı olarak izlenir. Daha distalde, sinir, humerus ile fleksör karpi ulnaris kasının ulnar başı arasında yer alır. Epikondil düzeyinde, sinir diğer düzeylere göre daha kalındır (tünel düzeyinde $6,8 \mathrm{~mm}^{2}$, distalinde 5,7 $\mathrm{mm}^{2}$, önkol proksimalinde $6,2 \mathrm{~mm}^{2}$ ). Bu kalınlık artışı fizyolojik olup, ulnar nöropati olarak değerlendirilmemelidir. Kübital tünel sendromunun temel ultrasonografik bulguları, sinirde fuziform hipoekoik kalınlaşma ve fasiküler paternde bozulmadır (Şekil 3). Sinirdeki kalınlık artışını değerlendirmek için, sinirin kesit alanı ölçülerek, karşı sağlıklı taraf veya diğer sağlıklı bireylerdeki ölçüler ile karşılaştırma yapılmaktadır. Kantitatif değerlendirme yapılmak istenirse, $9 \mathrm{~mm}^{2}$ eşik değer olarak kullanılabilir. Tünel içerisindeki yer kaplayıcı lezyonlar (mediyal kollateral bağ kalınlaşması, gangliyon, aksesuvar kas - ankoneus epitroklearis kası), ultrasonografik olarak kolayca tanınabilmektedir (Şekil 5).

\section{Ulnar Tünel Sendromu (Guyon Kanalı Sendromu)}

Ulnar tünel sendromu, distal ulnar sinirin Guyon kanalından geçerken sıkışması sonucu oluşur. Hamatum kancasının kırıkları veya kanal içi kitlesel lezyonlar, en sık nedenler arasındadır. Aksesuvar kas anomalisi, sık olarak görülür ve kadavra çalışmalarında $\% 22,4$ oranında saptanmıştır; genellikle bilateraldir. Ulnar sinir, US'de, en iyi pisiform kemik düzeyinde, ulnar arterin mediyalinde kanalda bulunan hiperekojen yağ dokusu içerisinde, küçük yuvarlak hipoekoik yapı olarak görülür. Yüksek çözünürlüklü US ile, yüzeyel ve derin motor dallara ayrılması ve yüzeyel dalların proksimali izlenebilir. US'de, kanal kitle lezyonu, ödem, fibrozis ve kemik anomalileri açısından değerlendirilmelidir (Şekil 10).

\section{Median Sinir Tuzak Nöropatileri \\ Anterior Interosseöz Nöropati (Kiloh-Nevin Sendromu)}

Anterior interosseöz sinir (AIOS), antekübital fossada median sinirden köken alır ve interosseöz membranın önünden el bileğine doğru iner. US'de sinir, 


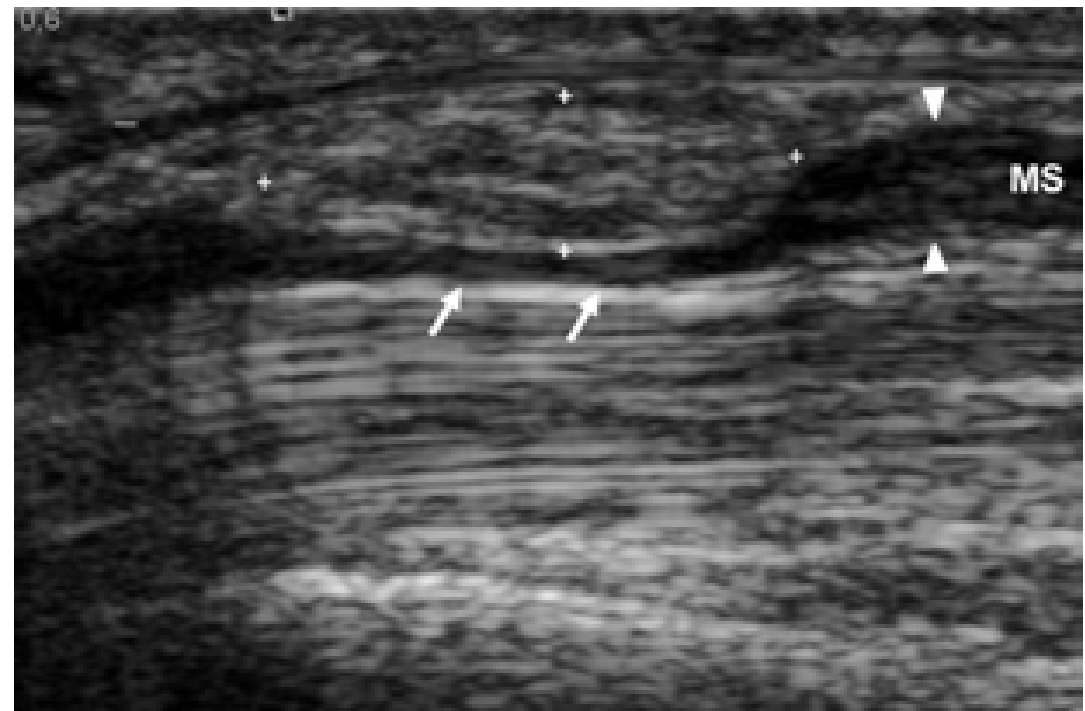

Şekil 11. Karpal tünel sendromu şikayetleri bulunan bir hastada, uzun aks US görüntüsünde, median sinire (MS) bası oluşturan lipom (kürsörler) izlenmektedir. Bası düzeyinde, median sinirde belirgin incelme ve düzleşme (oklar) izlenirken, sıkışma bölgesinin proksimalinde (ok başları) sinirde belirgin kalınlık artışı izlenmektedir.

median sinirin hemen derininde, interosseöz membranın üzerinde, oval yapıda, hipoekoik yapı olarak izlenir. AiOS'nin sıkışması, dirseğin üzerinde (sinir, median sinirin bir parçası iken) suprakondiller kemik çıkıntı veya Struthers bağı tarafindan ya da önkol düzeyinde sinir median sinirden ayrıldıktan sonra fleksör dijitorum süperfisiyel kasının humeroulnar ve radyal başını birleştiren tendinöz köprü tarafından basıya uğratılması ile gerçekleşebilir. AiOS, tek başına veya median sinir ile birlikte basıya uğratılabilir. Sinirin oldukça ince olması ve derinde yer alması nedeni ile, eğer neden yer kaplayıcı kitle lezyonu değil ise, ultrasonografik değerlendirmede genellikle bulgu izlenmemektedir; bazı olgularda, karşı taraf sinir ile karşılaştırıldığında, sinir kalınlaşmış olarak izlenebilir. Uzamış olgularda; fleksör pollisis longus, fleksör dijitorum profundus ve pronator kuadratus kaslarında, yağı ıtrofiye bağlı artmış ekojenite izlenebilir.

\section{Karpal Tünel Sendromu (KTS)}

KTS, en sık görülen tuzak nöropatidir. Prevalansının \%3-4 olduğu belirtilmektedir. Sinir sıkışmasının nedeni, karpal tünel boyutlarının azalması veya tünel içeriğinin artmasıdır. Tüneli oluşturan kemik yapıların genişlemesi (osteoartrit, mekanik aşırı kullanım, travma ve nadiren akromegali) veya volar retinakulumun kalınlaşması, tünel boyutlarını azaltır. Tünel içeriğinin artması, genellikle idiyopatiktir ve yer kaplayıcı lezyonlara (gangliyon, lipom, aksesuvar kas, amiloidoz veya sinoviyal hipertrofi vb.) bağlı olarak gelişir (Şekil 11).
Görüntülemeye, genellikle klinik - sinir ileti testlerinde uyuşmazlık veya tünel içerisinde yer kaplayıcı lezyon şüphesi halinde başvurulur. Karpal tünel, US ile oldukça iyi bir şekilde görüntülenebilmektedir; tüneli mediyalde çevreleyen pisiform ve hamatum ile lateralde çevreleyen skafoid ve trapeziuma ait gölgeler, tünelin her iki tarafında da görülmekte, ince bir volar fleksör retinakulum altında fleksör tendonlar ve median sinir, net olarak izlenebilir. Volar karpal retinakulum, anizotropiye bağlı kemiklerin üzerini örten ince hipoekoik bir yapı olarak izlenir. Fleksör tendonlar ile karşılaştırıldığında, median sinir hafif hipoekoik olarak izlenir. KTS'nin klasik tanı bulguları; fleksör retinakulumda yaylanma (hamate-pisiform ile trapezium-skafoid hattını birleştiren çizginin 2 mm'nin ötesinde olması), distalde median sinirde düzleşme ve proksimalde median sinirde kalınlık artışıdır; ancak bu üçlü, olguların sadece \%7'sinde görülür (Şekil 2). Bu bulgular içerisinde, sinirdeki kalınlık artışı, en sensitif ve spesifik ultrasonografik bulgudur. Normal median sinirin kesit alanı, pisiform düzeyinde 9-11 $\mathrm{mm}^{2}$ olarak belirtilmektedir. US'nin KTS'deki doğruluğunun \%95 olduğu bildirilmektedir. Yine, sinir içerisinde hiperemiye bağlı olarak, Doppler US'de vasküler kodlanma izlenebilir.

\section{ALT EKSTREMITE}

Alt ekstremitedeki tuzak nöropatileri, klinik muayene bulgularının zayıf olması ve elektrofizyolojik değerlendirmenin yeteri kadar güvenilir olmaması 
nedeni ile, genellikle tanı konusunda sıkıntı yaşanan klinik tablolardır. Bu nedenle, görüntüleme bulguları daha büyük önem taşımaktadır. Tuzak nöropatileri, genellikle üst ekstremitede olduğu gibi, fibröz veya fibro-osseöz tüneller düzeyinde mekanik nedenlerden ötürü veya spesifik bacak pozisyonlarında beliren, dinamik sinir yaralanmaları şeklinde ortaya çıkabilmektedir. ${ }^{[1,3,4,8,9]}$

\section{Lateral Femoral Kutanöz Sinir Tuzak Nöropatisi}

Lateral femoral kutanöz sinirin (LFKS) tuzak nöropatisi, meraljia parestetika olarak adlandırılır ve inguinal bağ seviyesinde meydana gelir. Ultrasonografik değerlendirme, hasta sırt üstü yatarken, transduser inguinal bağın 1-2 cm distaline yerleştirilir ve transvers aksta inceleme yapılır. Önce tensor fasya lata kası ve sartorius kası identifiye edilir ve her iki kas arasındaki boşlukta LFKS görüntülenir. Hiperekojen görünümdeki çevre yağ doku içerisinde, LFKS, hipoekoik ovoid bir yapı olarak tanınabilir. Sıkışma durumunda, sinirde enflamasyon ile uyumlu kalınlık artışı izlenir. Kesit alanı ölçümleri, sinirin ince bir yapıya sahip olması nedeni ile, US kürsörü ile yapılamayabilir ve bu durumda alan, sinirin iki aks boyutu ölçülerek, oval bir yapının formülü üzerinden hesaplanabilir. Çok ender olarak, LFKS'de nöroma geliştiği bildirilmiştir. Ayrıca US, oral medikasyona veya konservatif tedaviye yanıt alınamayan hastalarda şikayetlerinin azaltılması amacıyla yapılan enjeksiyon için de kılavuzluk sağlayabilmektedir.

\section{Siyatik Sinir Tuzak Nöropatisi}

Siyatik sinir, \%90 olguda piriformis adalesinin altından, \%10 olguda ise içinden geçer. Siyatik sinirin piriformis adalesi altında veya içinde sıkışmasına, piriformis sendromu denir ve en sık sıkışma nedenidir. Nedenler arasında, piriformis adalesinde kısalma, kontraktür, skar dokusu, hematom, heterotopik ossifikasyon ve travma sayılabilir. Siyatik sinirin ultrasonografik değerlendirmesi, bu düzeyde, ancak düşük frekanslı transduserler ile mümkün olmaktadır. MR'nin daha fazla bilgi verdiği bir sendrom olup, US'de yer kaplayıcı lezyonlar veya heterotopik ossifikasyon alanları görüntülenebilir.

\section{Tibial Sinir Sıkışma Tuzak Nöropatisi}

\section{Popliteal Sinir Sıkışması}

Tibial sinir, popliteal fossada politeal kist nedeniyle, popliteal kas rüptürü sonucu gelişen hematom basısına bağlı veya soleus kasının orijinindeki tendon tarafından sıkıştırılabilir. Karşı ekstremite ile karşılaştırmalı değerlendirme, sinirin sıkışma tanısını kolaylaştırır.

\section{Tarsal Tünel Sendromu}

Posterior tibial sinir ve dallarının tarsal tünel düzeyinde sıkışması sonucu ortaya çıkar. Tünel, mediyal malleolden, abduktor hallusis kasına dek uzanım gösterir ve posterior tibial, fleksör dijitorum ve fleksör hallusis longus (FHL) tendonlarını, tibial nörovasküler demeti ve dallarını içerir. US ile, tünelin anatomisi ve tibial sinir ortaya konabilir, yer kaplayıc lezyon açısından değerlendirme yapılabilir.

\section{Peroneal Sinir Tuzak Nöropatisi}

\section{Ortak Peroneal Sinir Sıkısma Sendromu}

Peroneal sinir, yüzeyel seyri nedeni ile fibula başı düzeyinde sıklıkla yaralanırve bu, alt ekstremitede görülen travmatik (proksimal fibula kırıkları, diz çıkıkları vb.) yaralanmalarında en sık rastlanan periferik sinir yaralanmasıdır. Travma sonrasında, alçı ve tespit cihazları da siniri sıkıştırabilmektedir. Bacak bacak üstüne atma alışkanlığı olanlarda, bilinç sorunu yaşayanlarda, uzun süre immobil kalanlarda veya anestezi altında tutulan hastalarda, eksternal bası ile sinir sıkışabilir. US ile, ortak peroneal sinirin kendisinin görüntülenmesi, trasesi, fibula başı ile olan ilişkisi ve komşuluğunda yer alabilecek yer kaplayıcı lezyonların ortaya konması, yüzeyel seyri sayesinde, oldukça başarılı bir şekilde yapılabilir (Şekil 12). Biseps femoris kası tendonunun posterior kenarı ve fibula başının ekojenik korteksi, sinirin yerini belirlemek için kullanılabilecek önemli anatomik yapılardır.

\section{Derin Peroneal Sinir Sıkışması}

Derin peroneal sinir, en sık olarak ayak bileği ekstansör retinakulum altında sıkışır ve buna, anterior tarsal tünel sendromu denir. Bu düzeyde, sinir tendonlar arasında sıkışabileceği gibi, osteofit, egzositoz ve tarsal kemikler nedeniyle de basıya uğrayabilir. Buna, gangliyon gibi yer kaplayan lezyonlar neden olabilir. Tekrarlayan dorsifleksiyon ve plantar fleksiyon, mekanik bası oluşturabilir.

\section{Morton Nöroması}

Morton nöroması, plantar dijital sinirin, karakteristik olarak metatars başları düzeyinde, transvers metatarsal bağın derininde bir tümör benzeri büyümesi olup, gerçek bir neoplastik nöroma değildir. US, Morton nöromasını görüntülemede oldukça etkili (duyarlılığı \%95-98 arasında) bir yöntemdir. Morton nöromasının ultrasonografik değerlendirmesi, semptomatik bölgede, dorsal ve plantar yüzden yapılmaktadır. US'de, intermetatarsal alanda hiper veya anekoik alanlar içeren, heterojen görünüm özelliğine sahip, hipoekoik kitlesel lezyon olarak görünür. Küçük nöromalar, US 


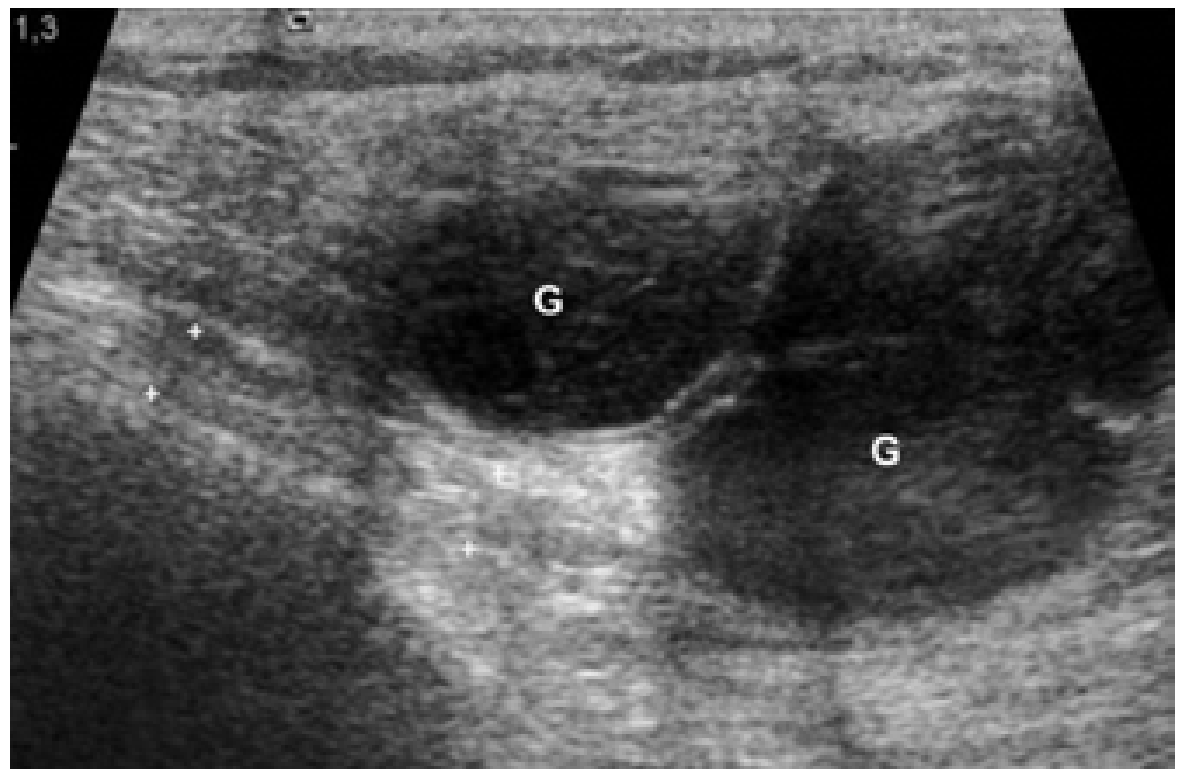

Şekil 12. Ortak peroneal sinirde (kürsörler) basıya neden olan, lobülasyon ve posterior akustik güçlenme gösteren gangliyon kisti (G).

çözünürlüğünün dışında kalıp görüntülenemeyebilir; ancak, çoğu sempomatik nöroma $5 \mathrm{~mm}$ 'den büyüktür ve US ile tanınabilir. Klinik olarak uygulanan Mulder testi, US'nin gerçek zamanlı olması nedeni ile, değerlendirme için kullanılabilir; değerlendirme yapılan tarafın ters tarafından yapılan baskı ile, nöromanın görüntülenmesinde artış olduğu belirtilmiştir. Ayırıcı tanıda, intermetatarsal bursit ve diğer kitlesel lezyonlar yer alır. Uzun aksta yapılan değerlendirme, kitle ile plantar dijital sinir devamlılı̆ını gösterebilir ve daha spesifik tanı konmasını sağlayabilir.

\section{Periferik Sinir Ultrasonografisinin Gelecekteki Yönü}

Günümüzde US, artmış çözünürlüğü ile periferik sinirlerin değerlendirilmesinde kabul edilmiş bir yöntem olmasına rağmen; gelecekte, yeterince iyi tanımlanmış kantitatif kriterlerin ve ultrasonografik skorların oluşturulması, intra- ve inter-rater güvenilirliğin arttırılması veya tuzak nöropatilerin immün-aracılı nöropatilerden ayırt edilmesi açısından önemli bir gelişme olacaktır. Güvenilir ultrasonografik biyomarkerlerin geliştirilmesi, tedavinin monitorize edilmesinde kullanılabilir; böylece, tanının ve terapötik etkinliğin arttırılması sağlanabilir. Sonoelastografi gibi yeni teknolojiler ile elde edilen verilerin, sinir kesit alanı değerleri ile kombine edilmesi, tanısal duyarlıı̆̆ı arttıracak gibi görünmektedir. Ultrasonografik kontrast maddelerin kullanılması, tuzak nöropatilerinde izlenebilen düşük akımlı mikrovaskülaritenin ölçülebilirliğini sağlayacaktır. Üç boyutlu (3D) ultrasonografik görüntüleme, sinirin anatomik varyasyonlarının daha iyi anlaşılması ve çevre anatomik yapılar ile ilişkisinin gösterilmesinde kullanılabilir görünmektedir.

\section{SONUÇ}

Tuzak nöropatiler, yaygın görülen ve ciddi morbiditiye neden olan klinik tablolardır. Erken tanı ve tedavinin erken dönemde başlatılması, olası hasarın en aza indirilmesi açısından önemlidir. US, sinir lezyonlarının lokalizasyonunun tam olarak yapılabilmesi, sinirin kendisini gösterebilmesi, çevre dokular hakkında bilgi vermesi ve tedavi amaçlı uygulamalara kılavuzluk etmesi açısından tuzak nöropatilerde öne çıkan yöntemlerdendir.

\section{KAYNAKLAR}

1. Cartwright MS, Walker FO. Neuromuscular ultrasound in common entrapment neuropathies. Muscle Nerve 2013;48(5):696-704. CrossRef

2. Martinoli C, Bianchi S, Pugliese F, Bacigalupo L, Gauglio C, Valle M, Derchi LE. Sonography of entrapment neuropathies in the upper limb (wrist excluded). J Clin Ultrasound 2004;32(9):438-50.

3. Dong Q, Jacobson JA, Jamadar DA, Gandikota G, Brandon C, Morag Y, Fessell DP, Kim SM. Entrapment neuropathies in the upper and lower limbs: anatomy and MRI features. Radiol Res Pract 2012;2012:230679. CrossRef

4. Hochman MG, Zilberfarb JL. Nerves in a pinch: imaging of nerve compression syndromes. Radiol Clin North Am 2004;42(1):221-45. 
5. Toros T, Karabay N, Ozaksar K, Sugun TS, Kayalar M, Bal E. Evaluation of peripheral nerves of the upper limb with ultrasonography: a comparison of ultrasonographic examination and the intra-operative findings. J Bone Joint Surg Br 2009;91(6):762-65. CrossRef

6. Mallouhi A, Pülzl P, Trieb T, Piza H, Bodner G. Predictors of carpal tunnel syndrome: accuracy of gray-scale and color Doppler sonography. AJR Am J Roentgenol 2006;186(5):1240-5.

7. Miller TT, Reinus WR. Nerve entrapment syndromes of the elbow, forearm, and wrist. AJR Am J Roentgenol 2010;195(3):585-94. CrossRef
8. Donovan A, Rosenberg ZS, Cavalcanti CF. MR imaging of entrapment neuropathies of the lower extremity. Part 2. The knee, leg, ankle, and foot. Radiographics 2010;30(4):100119. CrossRef

9. Peer S, Kovacs P, Harpf C, Bodner G. High-resolution sonography of lower extremity peripheral nerves: anatomic correlation and spectrum of disease. J Ultrasound Med 2002;21(3):315-22. 